report points out, some tests will give information about many other metabolic disorders in addition to phenylketonuria and even reveal further new disorders. I therefore think it important that we should not drift piecemeal into Guthrie testing without considering the mechanics and economics of screening in the country as a whole.

Finally may I illustrate the perversity of the laws of sampling in detecting these very rare diseases. The working party report points out that the frequency in Britain of phenylketonuria is probably about 1 in 10,000 births, but Dr. L. I. Woolf tested over 20,000 infants and Dr. G. M. Komrower tested nearly 10,000 infants withou finding a case. We have been screening the newborn infants in our obstetric hospital for two years by the Scriver paper chromatographic technique on plasma; the 450th infant we tested had phenylketonuria, but do not wish to claim that the incidence of phenylketonuria is greater at University College Hospital than in Oxford or Manchester. -I am, etc.,

$$
\begin{aligned}
& \text { DAvID C. CusWoRTH. } \\
& \text { University College Hospital } \\
& \text { Medical School, }
\end{aligned}
$$

\section{Transplantation Problems}

SIR,-Dr. D. K. C. Cooper's brief survey of the literature on cardiac transplantation (19 October, p. 174) indicates that there were many gaps in our knowledge about the behaviour of the transplanted heart before human heart transplantation was started. The natural history of the canine transplanted heart was not so well worked out as the canine transplanted kidney; a technique which interrupted the conducting system of the heart was not to some people's liking; and the role of the coronary vessels in rejection was not appreciated. The consequences of right atrial dilatation are still not generally appreciated in spite of the fact that pulmonary embolism has occurred at a time when rejection was suspected.

In the early stages after transplanting the canine heart to the neck it is difficult sometimes to be absolutely certain that functional abnormalities are not due to causes other than technical. Kinking of the right outflow tract can cause functional disturbances, but they are quickly reversed when the obstruction is relieved. Hypothermia certainly causes incoordinated beats and arrhythmias for an hour or so after establishing the new circulation. At room temperature coordinated beats occur spontaneously within 10 minutes, and the rate is always above $120 /$ min. Accordingly, hypothermia has been abandoned in our experiments. I have had occasion to avoid hypothermia because of the initial problems it introduces in order to avoid all possible technical interpretations in studying the behaviour of the second set heart. The recipients were sensitized with skin grafts, and one week after rejection was complete the heart from the same animal was transplanted. Because second set kidneys can function quite well for some hours, I have been surprised to find that the second set heart transplant is in functional difficulties within a few minutes. In three consecutive second set hearts, a co-ordinated beat occurred within 10 minutes, but the rate was slow
$(80 / \mathrm{min}$.$) . At 30$ minutes, all three suddenly became cyanosed and collapsed. With gentle massage they recovered sufficiently to continue beating feebly and slowly at rates of about $80 / \mathrm{min}$. for several hours. The E.C.G. of such hearts is abnormal for the early postoperative stage, and arteriography shows vascular spasm-especially in the small peripheral vessels. There is also aortic incompetence. These features have been reported previously as terminal signs of heart transplant rejection (15 June, p. 695). The central role of vascular spasm is common to heart and kidney transplant rejection in both first and second set conditions.

It has been pointed out that the second kidney from a different donor may become involved in a second set reaction. ${ }^{1}$ Clinically, there have been similar experiences. ${ }^{2}$ I have indicated before that it may be difficult to rule out some technical cause for such early anurias; three out of seven second transplants from different donors failed to function, ${ }^{3}$ and a technical cause was assigned on the basis of the general theory pertaining at that time.

In four consecutive second heart transplants from different donors signs of functional abnormality have been encountered in all, but not so dramatically as in same-donor second sets. The early signs of immunological damage appear to be: slow rate of contractions at $80 / \mathrm{min}$., a change from co-ordinated beats to incoordinated muscle twitchings after some hours, vascular spasm of the coronary tree with no vasodilatation and faster rate after the injection of sodium diatrizoate (Hypaque), and cyanosis of the myocardium. Similar disturbances of behaviour in the allotransplanted heart may be encountered in humans with proved preexisting cytotoxins, and this serological feature should bias one against technical interpretations. Unless the human behaves very differently under immunosuppression, second heart transplants are going to be of very limited value.-I am, etc.,

\section{Royal Postgraduate Medical School
ondon W.12. \\ W. J. DEMPSTER. \\ REFERENCES \\ Dempster, W. J., and Kountz, S. L., Rev. Surg., 1966, 23, 5 . \\ Takamoto, S., Straffon, R. A., and Kolf, W. J.,
Transplantation, 1967, 5, 854. 3 Dempster, W. J., Brit. F. Surg., 1953, 40, 447.}

\section{Keloids}

SIR,-Discussion about keloids invariably provokes controversy. We would disagree with several of the statements contained in your leading árticle (5 October, p. 3). Hypertrophic scars are common in white people, particularly older children and young adults. After growing for about three months they often remain static for a few months and tend to regress in the course of the next year or 18 month. The term "keloid" is better reserved for those scars which continue to progress for long beyond these times and may remain active and enlarge for many years. While common in black-skinned people they are uncommon on the white skin, though seen over the sternum and in the ear lobes after piercing for the insertion of ear-rings.

The surgeon may rightly be blamed for the sins which you enumerate-suturing under tension, cutting across natural skin creases, and failing to graft skin defects. These errors may well produce bad scars which may become hypertrophic, but we know of no evidence that a "bad" scar is more likely to produce a true keloid than a "good" scar.

Treatment of the scar is never easy, but we were surprised that you made no mention of the use of local steroids. These are now widely used by dermatologists and surgeons, either in the form of local applications or by intralesional injections. Injection of triamcinolone is a simple and safe treatment which may flatten an established keloid or prevent its recurrence after surgical removal.-We are, etc.,

IAN F. K. MUIR.

H. T. H. WILSON.

Central Middlesex Hospital,

London N.W.10.

SIR,- - In your leading article (5 October, p. 3) you mentioned varied methods in the treatment of keloids-for example, $x$-ray therapy, excision, and the combination of excision, grafting, and irradiation. May I suggest another method of treatment which I have practised with promising results during the past few years-namely, the infiltration of the keloid area with hydrocortisone under local anaesthesia?

A woman, 34 years of age, after operation for removal of a tubo-ovarian cyst, developed keloid in the scar which caused itching and pain. Local application of cortisone relieved the itching, but had no effect on the appearance of the scar. The following year she underwent a minor gynaecological operation, and while she was under general anaesthesia hydrocortisone was injected in and around the keloid. Within six weeks the keloid disappeared, leaving a normal white scar.

A girl 21 years of age developed a large keloid two years after appendicectomy. Hydrocortisone was infiltrated under local anaesthesia. After three weeks the lesion became flatter, and after six weeks disappeared with the exception of a small area at its upper end. After a second injection the rest of the keloid disappeared.

A woman 34 years of age developed a keloid after caesarean section. Three years later a second caesarean was performed during which the keloid scar was excised. After three months typical keloid again developed. Infiltration with hydrocortisone changed the keloid into normal scar.

A woman 23 years of age after operation for ovarian cyst developed a normal scar. Three years later she was again operated on for an ectopic pregnancy. The old scar was excised, but the new one developed keloid after some months. She complained of itching and pain in the scar. Local infiltration with hydrocortisone again resulted in regression of the keloid after five weeks.

I must mention one case of failure, and this was in a coloured patient.

The exact action of cortisone is still obscure. Atkinson ${ }^{2}$ and Sulzberger ${ }^{2}$ suggest that cortisone produces rapid absorption of inflammatory exudates of collagen and of elastic fibres. This method of treating keloid is so simple that it should first be tried before any other drastic procedure is contemplated. -I am, etc.,

Londun W.1.

\section{E. SCHLEYER-SAUNDERS.}

Atkinson, W. B., Goldman, L., Suskind, R. R and Baskett, J., f. Histochem Cytochem., 1954 $2,479$.

2 Sudzberger, M. B., Arch. Derm., 1963, 87, 456. 